Disponível em

http://www.anpad.org.br/rac

RAC, Rio de Janeiro, v. 18, n. 5, art. 4, pp. 627-649, Set./Out. 2014

http://dx.doi.org/10.1590/1982-7849rac20141659

$((c))$ EY-No

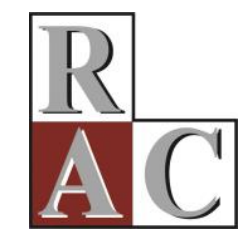

\title{
Pesquisa, Ensino e Prática de Gestão de Operações: Consonâncias e Divergências entre Três Mundos
}

\section{Research, Teaching and Practice of Operations Management: Consonances and Divergences among Three Worlds}

Jurandir Peinado

E-mail: jurandirpeinado@gmail.com Universidade Tecnológica Federal do Paraná - UTFPR Av. Sete de Setembro, 3165, Rebouças, 80230-901, Curitiba, PR, Brasil.

Alexandre Reis Graeml E-mail: graeml@utfpr.edu.br Universidade Tecnológica Federal do Paraná - UTFPR Av. Sete de Setembro, 3165, Rebouças, 80230-901, Curitiba, PR, Brasil. 


\title{
Resumo
}

Esta pesquisa analisou a importância atribuída às temáticas da Gestão de Operações a partir das perspectivas da pesquisa, do ensino e da prática empresarial. Os dados foram colhidos por meio de uma survey, também, analisando-se outras evidências da atenção de pesquisadores, professores e praticantes ao corpo de conhecimento da área. A análise baseada na survey não evidenciou diferenças significativas entre os três grupos de profissionais. Alguma dissonância se revelou, contudo, nas atividades profissionais cotidianas também analisadas. Dois temas figuraram entre os 10 mais presentes no dia a dia de pesquisadores, professores e praticantes de Gestão de Operações (Estratégias e políticas de produção e Gerenciamento da qualidade). Três temas (Gerenciamento das informações de operações, Sistemas de produção enxuta e Projeto, mensuração e melhoria do trabalho) destacaram-se entre os mais valorizados por pesquisadores e praticantes. Um tema (Gerenciamento da produção e processos) apresentou-se entre os 10 mais relevantes para professores e praticantes. Outros dois temas (Gestão da cadeia de suprimentos e Gerência de projetos) apareceram com frequência na pesquisa e no ensino.

Palavras-chave: gestão de operações; temas de estudo; pesquisa; ensino; prática.

\begin{abstract}
This paper analyzes the importance assigned to Operations Management themes by researchers, educators and practitioners in the field. Data were collected by means of a survey and also by analyzing other evidence of concern to researchers, educators and practitioners. The analysis based on the survey did not reveal any significant differences between the three groups of professionals. Some dissonance was perceived, however, in the involvement of these professionals with such themes in their daily activities. Two themes appear among the ten most frequent themes depicted for the three professional groups (Production strategy and policies; and Quality management). Three themes (Operations information management; Lean production systems; and Work design, measurement and improvement) are among the most prevalent ones for researchers and practitioners. One theme (Operations and process management) is among the ten most relevant for educators and practitioners. Two other themes (Supply chain management; and Project management) frequently appear to be important for researchers and educators.
\end{abstract}

Key words: operations management; research themes; research; education; practice. 


\section{Introdução}

A indissociabilidade entre ensino, pesquisa e extensão foi consagrada pelo art. 207 da Constituição da República Federativa do Brasil de 1988 (2014), que determina que "as universidades gozam de autonomia didático-científica, administrativa e de gestão financeira e patrimonial, e obedecerão ao princípio de indissociabilidade entre ensino, pesquisa e extensão" (p. 121). Diversos autores reconhecem que, há muito tempo, a necessidade da cooperação entre a universidade e as empresas passou a ocupar lugar de destaque na atenção dos administradores, professores, órgãos governamentais e entidades empresariais (Grynszpan, 1999; Marcovitch, 1999).

A pesquisa representa o mecanismo de criação e gênese do conhecimento. Seu processo produtivo tem sua maior expressão nos trabalhos publicados por pesquisadores, cujo resultado deve atualizar constantemente os conteúdos programáticos do ensino. Ford et al. (2003) afirmam haver um paradoxo entre pesquisa e prática empresarial: por um lado, os pesquisadores lamentam o fato do pouco impacto de seus trabalhos na prática gerencial, por outro lado, os executivos procuram conhecimentos que possam ajudá-los a melhorar o desempenho gerencial, mas raramente consultam os trabalhos dos pesquisadores que são vistos com frequência como incompreensíveis e irrelevantes para os desafios do dia a dia.

O ensino, por sua vez, representa o mecanismo de difusão do conhecimento e seu processo produtivo ocorre predominantemente no âmbito das salas de aula. Chalmovich (1999) explica que a missão original das universidades consistia em criar, preservar e transmitir o conhecimento, já a incorporação da função de transferir conhecimento para a indústria data do início da revolução industrial. $\mathrm{O}$ autor toma como exemplo o desenvolvimento da química orgânica da Alemanha do século XIX, que dificilmente pode ser separado do crescimento da indústria de corantes sintéticos naquela época e naquele país.

Já a extensão representa a objetivação do conhecimento, com a operacionalização da relação entre a teoria e a prática, a democratização do saber acadêmico e o retorno desse saber à universidade, testado e reelaborado fora dos ambientes universitários. Marcovitch (1999) lembra que, nos dias atuais, as corporações empregam pessoal de nível universitário na gestão estratégica de seus negócios. O autor adverte que, para que haja cooperação em termos ideais, é importante que as universidades tenham efetivas condições de ajudar na modernização dos processos produtivos das empresas.

Assim, o alinhamento entre pesquisa, ensino e extensão é considerado um elemento de excelência de uma universidade, representando uma de suas virtudes e expressão de seu compromisso social. Quando ele ocorre, o resultado das pesquisas deve se tornar conteúdo de ensino e influenciar a vida da sociedade. Contudo trabalhos apresentados por Rynes, Bartunek e Daft (2001), Starkey e Madan (2001), Spell (2001) e Abrahamson e Eisenman (2001), entre outros, alertam para a existência de um gap considerável e falta de alinhamento entre pesquisa, ensino e extensão.

Este artigo tem por objetivo contrastar as visões de pesquisadores, professores e praticantes sobre a importância que atribuem aos temas da Gestão de Operações. Inicialmente, as três perspectivas foram capturadas a partir da abordagem direta dos pesquisadores, professores e praticantes, por meio de uma survey. A seguir, cada uma delas foi também capturada a partir de um procedimento específico: a perspectiva dos pesquisadores foi capturada por meio do mapeamento da demanda por espaço editorial para publicação de artigos sobre as diversas temáticas; a perspectiva do ensino foi capturada por meio do levantamento dos conteúdos programáticos nos ementários das disciplinas de Gestão de Operações dos cursos de Administração; e a perspectiva dos praticantes foi obtida pelo levantamento dos conteúdos em Gestão de Operações mais valorizados pelas organizações industriais, com base na análise dos conteúdos dos documentos que orientam seus sistemas de produção.

O desenvolvimento da presente pesquisa se justifica, do ponto de vista prático, pela possibilidade de divulgação dos resultados para pesquisadores interessados no tema, para professores dos cursos de Administração em que os conteúdos são ministrados e para os praticantes da Gestão de Operações, como 
forma de orientar seus esforços de modo a que consigam contribuir para tornar a Gestão de Operações mais relevante para as empresas e a sociedade como um todo. Também se justifica pela possibilidade de divulgação dos temas em Gestão de Operações considerados mais importantes pelos praticantes, para pesquisadores interessados na área e professores dos cursos de Administração, como forma de alinhar seus esforços às necessidades de quem utiliza os conhecimentos da área na sua prática cotidiana, em ambiente empresarial. Ou, no caso de os praticantes não estarem conseguindo perceber o potencial benefício de determinados temas considerados importantes pelos acadêmicos, a identificação da dissonância de percepção de valor também pode levar a uma tentativa, por parte dos primeiros, de apresentar tais temas de uma forma que ressalte sua relevância.

A partir de uma perspectiva teórica, a realização da pesquisa se justifica pela constatação da existência de inúmeros trabalhos estrangeiros, como as pesquisas conduzidas por Smith e Robey (1973), Green, Newsom e Jones (1977), Berry, Watson e Greenwood (1978), Westbrook (1994), Levenburg (1996), Machuca e Luque (2003), Slack, Lewis e Bates (2004) e Schmenner, Wassenhove, Ketokivi, Heyl e Lusch (2009), apenas para citar alguns dos que discutem a importância da realização deste tipo de pesquisa. Vários desses trabalhos mencionam a existência de uma lacuna entre a teoria acadêmica e sua utilização na prática da Gestão de Operações, o que clama por verificação no sentido de se tal dissonância também ocorre no Brasil, pois não foram encontrados estudos nacionais específicos que avaliem o grau de alinhamento da teoria, oriunda das pesquisas científicas, ao que é ensinado nos cursos de graduação e praticado pelos gestores e demais funcionários da área de operações no ambiente empresarial.

Nas seções seguintes são apresentadas pesquisas anteriores que procuraram capturar a impressão dos pesquisadores, professores e praticantes da Gestão de Operações sobre a aplicação dos conceitos dessa disciplina ao seu dia a dia. Depois, discute-se a metodologia utilizada na coleta e na análise dos dados de campo utilizados para tentar compreender a relevância atribuída a cada temática da Gestão de Operações na perspectiva dos participantes da pesquisa. Em seguida, esses dados são apresentados e analisados para, ao final, serem sumarizados os principais achados e discutidas as limitações da pesquisa e possíveis trabalhos futuros.

\section{Pesquisa, Ensino e Prática em Gestão de Operações}

\section{A pesquisa científica sobre gestão de operações}

O estudo e acompanhamento da evolução da pesquisa científica tem sido tema de um número considerável de publicações científicas em várias áreas do conhecimento. Nas últimas décadas, vários artigos sobre o assunto foram publicados em periódicos de Gestão de Operações.

Já no lançamento do periódico Journal of Operations Management (JOM), Buffa (1980) anunciou a preocupação em balizar os temas de pesquisa na área, propondo uma lista de assuntos para pesquisas científicas em Gestão de Operações. Neste mesmo primeiro volume do JOM, Chase (1980) publicou um trabalho sobre a evolução e classificação da pesquisa em Gestão de Operações com base em artigos contidos em quatro periódicos de renome: Decision Sciences, AIIE Transactions, Management Science e International Journal of Production Research. Mais recentemente, em 2007, o periódico JOM destinou um número especial, com 16 artigos, à análise dos tópicos abordados pela Gestão de Operações, considerando sua evolução histórica desde o século XVI até o XXI (Sprague, 2007).

No Brasil, também são inúmeros os trabalhos sobre a pesquisa da produção científica em Gestão de Operações. Um dos trabalhos seminais sobre o assunto, e talvez o mais conhecido, foi realizado por Arkader (2003). A autora pesquisou e classificou 221 trabalhos publicados nos anais do Enanpad, no período de 1980 a 2002, 82 artigos publicados na RAE, no período entre 1961 e 2001, 33 artigos publicados na Rausp, de 1978 a 2001, e 18 artigos publicados na RAC, de 1997 a 2001. Arkader (2003) concluiu que, até então, a pesquisa em Gestão de Operações ainda não havia conseguido "encontrar sua 
identidade na busca de respostas a problemas de natureza intrinsecamente estratégica, estando ainda marcada por grande indissociação com a engenharia" (p. 79).

Corrêa, Paiva e Mendes (2010) fazem um relato sobre a evolução da pesquisa em Gestão de Operações no Brasil, confirmando a influência da área da Engenharia de Produção, especialmente pela presença de artigos com modelagem matemática em muitos trabalhos da área de Administração. Martins, Rossoni, Csillag, Martins e Pereira (2010) analisam a rede de pesquisadores que publicam no campo de Gestão de Operações no Brasil, baseando-se em 2.668 artigos publicados entre 1997 e 2009, usando como fonte de dados as revistas RAE, RAC, RAUSP, BAR e Gestão e Produção. Em outra recente pesquisa sobre a produção científica em Gestão de Operações, que contemplou os últimos 10 anos das principais revistas da área de Administração, Paiva e Brito (2013) analisam a relevância e o rigor nos temas e métodos de pesquisa utilizados por pesquisadores brasileiros de Gestão de Operações. Assim, concluíram que houve convergência entre o que foi publicado por autores brasileiros nos periódicos científicos nacionais e os temas frequentemente discutidos nos periódicos estrangeiros, com destaque para supply chain management e estratégia de operações.

\section{O ensino sobre gestão de operações}

Trabalhos que refletem a preocupação a respeito dos temas que devem compor o conteúdo programático no ensino de Gestão de Operações remontam à longa data. Em um trabalho seminal sobre o tema, Goetz (1959) já apontava a dificuldade na construção de uma grade curricular eclética o suficiente para abordar a complexidade da Gestão de Operações. Na visão desse autor, o elenco de temas teria de envolver não apenas as técnicas de engenharia necessárias à compreensão dos diversos processos produtivos da manufatura, mas também desenvolver habilidades de administração na construção de estratégias que permitissem a condução eficaz de equipes de pessoas que trabalham em processos produtivos. Segundo Corrêa et al. (2010), apesar de o tema ser discutido desde meados do século passado, a Gestão de Operações, vista como uma disciplina nos cursos de graduação em Administração, cresceu vertiginosamente em conteúdo somente a partir da década de 1980, como resultado indireto dos inúmeros problemas encontrados pela indústria na época. Muitas escolas de Administração aumentaram o número e a carga horária das disciplinas ligadas à Gestão de Operações em resposta à pressão da American Assembly of Collegiate Schools of Business (Berry \& Lancaster, 1992; Berry, Watson, \& Greenwood, 1978; Young, Baird, \& Pullman, 1996).

Ainda no final da década de 1970, Berry et al. (1978) levantaram os tópicos que deveriam fazer parte da matriz curricular em Gestão de Operações, por meio de uma survey enviada a professores e praticantes. Os resultados indicaram que os professores entendiam que devia haver equilíbrio entre teoria e prática. Curiosamente, e embora talvez se pudesse esperar o oposto, os praticantes percebiam, de acordo com esses autores, a necessidade do curso ter orientação mais conceitual e menos técnica.

\section{A prática empresarial da gestão de operações}

Várias pesquisas buscam identificar os temas de Gestão de Operações que fazem parte do dia a dia da prática empresarial. No âmbito nacional, Vanalle e Salles (2011) entrevistaram profissionais das áreas de produção de 14 empresas fornecedoras de montadoras, levantando os tópicos da Gestão de Operações mais importantes para satisfazer as rigorosas demandas dos seus clientes. Os temas identificados foram: nível tecnológico, capacidade de P\&D, capacidade dos funcionários, formação dos funcionários em qualidade, suprimentos com zero defeitos, agilidade dos canais de comunicação, melhoria contínua, custos industriais, capacidade de projeto, cumprimento da ISO 9000 e controle da qualidade.

Alves, Nogueira e Bento (2011) levantaram as estratégias de produção de seis montadoras de motores para automóveis instaladas no Brasil, em uma pesquisa realizada por meio de entrevistas com os principais responsáveis pelas unidades produtoras. As ações consideradas mais importantes para a operação produtiva, na opinião desses praticantes, estão descritas na Tabela 1. 
Tabela 1

Ações Consideradas mais Importantes Relativas à Operação Produtiva

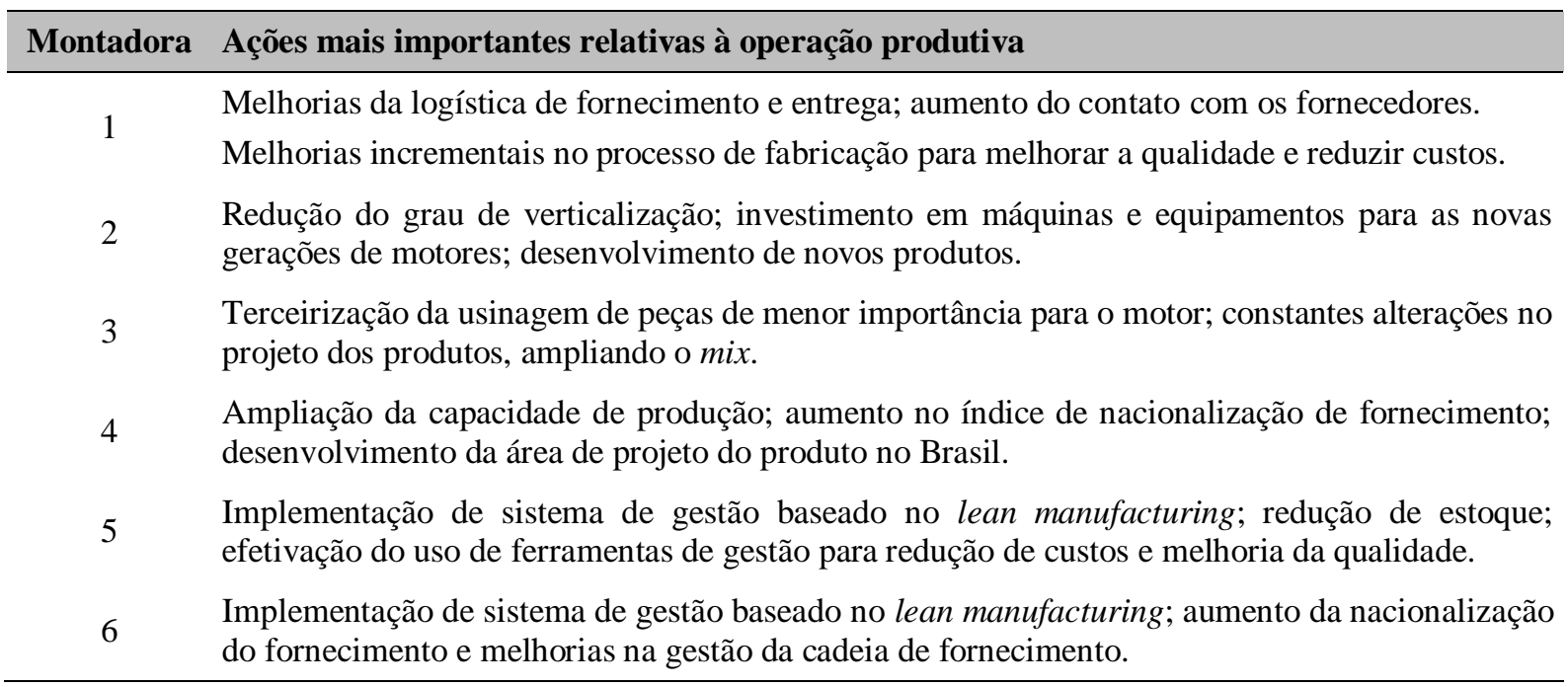

Nota. Fonte: adaptado de Alves, A. G., Filho, Nogueira, E., \& Bento, P. E. G. (2011). Análise das estratégias de produção de montadoras de motores para automóveis (p. 615). Gestão e Produção, 18(3), 603-618. doi: 10.1590/S0104$530 \times 2011000300012$

Em um trabalho sobre práticas de Gestão de Operações utilizadas em grandes indústrias, Saurin, Ribeiro e Marodin (2010) realizaram um levantamento a respeito do processo de implantação do SPE em 47 empresas do Brasil e do exterior, sendo que 21 delas pertencem ao ramo automotivo e 20 têm planta no Brasil. O estudo apontou que os principais motivos das empresas para a adoção do SPE são a necessidade de melhorar a competitividade e a percepção da efetividade do SPE no combate a problemas críticos de produção. Já as dificuldades encontradas mais frequentemente foram a resistência das pessoas e a adaptação à cultura organizacional de conceitos e práticas demandados pelo SPE. Na Tabela 2, expõe-se uma listagem em ordem de importância das práticas prioritárias do SPE, conforme as empresas pesquisadas.

Tabela 2

Práticas Consideradas Prioritárias para o SPE

\begin{tabular}{clcl}
\hline Posição & Práticas prioritárias & Posição & Práticas prioritárias \\
\hline 1 & Produção puxada & 10 & Lean accounting \\
2 & Padronização do trabalho & 11 & Logística lean \\
3 & Gerenciamento visual & 12 & Lean design \\
4 & Controle da qualidade/zero defeitos & 13 & Flexibilização da mão de obra/multifunção \\
5 & Mapeamento de fluxo de valor & 14 & Produção enxuta e SSMA (segurança, saúde e meio \\
& & & ambiente) \\
6 & Kaizen e solução de problemas & 15 & Autonomação \\
7 & Troca rápida de ferramentas & 16 & Lean office \\
8 & Manutenção produtiva total & 17 & Lean service \\
9 & Nivelamento da produção & 18 & Outras \\
\hline
\end{tabular}

Nota. Fonte: adaptado de Saurin, T. A., Ribeiro, J. L. D., \& Marodin, G. A. (2010). Identificação de oportunidades de pesquisa a partir de um levantamento da implantação da produção enxuta em empresas do Brasil e do exterior (p. 839). Gestão e Produção, 17(4), 829-841. doi: 10.1590/S0104-530X2010000400015 


\section{Procedimentos Metodológicos}

\section{Coleta e análise de dados de pesquisadores, professores e praticantes - survey}

Em primeiro lugar, os participantes da pesquisa foram convidados a responder a um questionário com perguntas de escala Likert de sete pontos, enviado por e-mail. O questionário constou de 45 perguntas, elaboradas de forma a cobrir as diversas áreas temáticas da Gestão de Operações, conforme proposta de Peinado e Graeml (2013), e procurando medir a importância que os respondentes atribuíam a cada uma delas. Uma oitava alternativa, além das sete opções da escala Likert, foi disponibilizada para permitir que aqueles que não tivessem opinião formada, ou desconhecessem o tema, pudessem expressar essa situação.

A opção pela análise quantitativa decorreu da intenção de generalização dos resultados, a partir da análise dos dados coletados para a amostra de pesquisa, como sugerido por Babbie (2001). A validação de face foi obtida por meio do pré-teste do questionário com respondentes que ocupam cargos em Gerência de Operações em suas empresas. Para isso, foi utilizado um grupo de 15 respondentes, composto por oito profissionais com formação em Administração e outros sete com formação em Engenharia de Produção. Não houve preocupação em validar as questões da survey com pesquisadores e professores porque ela foi estruturada de uma forma praticamente direta a partir do mapeamento consolidado de temáticas proposto por Peinado e Graeml (2013), que tinha origem em periódicos acadêmicos. Ainda assim foi realizado um teste piloto com 70 professores para verificar se a dispersão das respostas ao longo da escala Likert utilizada era satisfatória, de modo a permitir o eficiente tratamento dos dados pelos métodos estatísticos pretendidos.

\section{Seleção de pesquisadores para a amostra da survey}

Para a composição do subgrupo de pesquisadores, foram convidados 36 pesquisadores. Esses pesquisadores publicaram mais de cinco artigos abordando temas da Gestão de Operações em periódicos nacionais de relevância, no período compreendido de 2001 a 2010. O contato para envio do questionário aos 36 pesquisadores deste subgrupo da amostra foi obtido por meio da consulta ao Currículo Lattes individual de cada um. Ao final, 12 pesquisadores responderam ao questionário.

\section{Seleção de professores para a amostra da survey}

Para a composição do subgrupo dos professores, foram convidados professores que ministram disciplinas relacionadas à Gestão de Operações em cursos de graduação em Administração de 47 instituições de ensino. Esses professores fazem parte dos quadros de instituições escolhidas a partir de três critérios: o primeiro critério procurou assegurar a participação de professores de instituições de ensino com destaque na produção científica sobre Gestão de Operações, medido com base no número de artigos publicados por pesquisadores a elas afiliados nos periódicos científicos nacionais de relevância, no período de 2001 a 2010. Seguindo esse critério de escolha, 61 professores de 10 instituições foram convidados a participar, sendo que, no final da pesquisa, 24 deles responderam ao questionário. O segundo critério procurou incluir professores de cursos de Administração de reconhecida excelência. Desta forma, foram convidados a participar da survey professores de todos os 17 cursos de Administração que obtiveram faixa cinco no Conceito Preliminar de Curso (CPC) do Inep. Este critério de escolha permitiu encontrar 137 professores que foram convidados a participar da pesquisa, sendo que 56 deles responderam ao questionário. Para compor a terceira parte deste grupo amostral, foram convidados a participar da pesquisa professores de 20 cursos de Administração que obtiveram faixa três no CPC do Inep. Seguindo este critério de escolha, 52 professores receberam o convite, sendo que 11 aceitaram participar. A identificação dos professores que ministram disciplinas diretamente relacionadas à Gestão de Operações nos cursos de Administração selecionados para participar do estudo foi realizada por meio de uma pesquisa nos websites dos cursos e consulta ao 
currículo Lattes dos professores. O contato para envio do questionário aos 250 professores das 47 instituições selecionadas para o estudo foi obtido no currículo Lattes de cada professor.

\section{Seleção dos praticantes para a amostra da survey}

Para compor o grupo de praticantes, foi utilizada uma relação composta por 1.300 profissionais em Gestão de Operações, incluindo gerentes, supervisores ou coordenadores de produção que atuam em empresas do ramo automotivo. Os profissionais fazem parte de um cadastro que vem sendo formado pelos autores deste trabalho ao longo dos últimos anos. A utilização desse cadastro para a composição da amostra se justifica pela facilidade de aplicação da survey a esse grupo de profissionais que já haviam tido um relacionamento prévio com a universidade e com os autores e por acreditar-se que empresas atuantes no ramo automotivo têm seu processo de Gestão de Operações amadurecido, em decorrência das fortes exigências de desempenho no dia a dia e adequações a várias normativas de qualidade demandadas pelas montadoras de automóveis.

\section{Ferramentas e técnicas de análise dos dados obtidos a partir da survey}

Os dados obtidos na survey foram analisados estatisticamente com o auxílio do software SPSS (Statistical Package for the Social Sciences), versão 15. Procedeu-se, então, a uma análise descritiva de cada uma das 45 variáveis quantitativas por meio da AED (análise exploratória de dados), que consiste, basicamente, em explorar os dados por meio de técnicas gráficas. A seguir, foi executada uma comparação das médias pela ANOVA com testes post hoc de Tukey, como recomendado por Dancey e Reidy (2006) e Field (2009).

\section{Coleta de dados da perspectiva dos pesquisadores - análise de publicações}

A seguir, como uma segunda fonte de dados, a perspectiva dos pesquisadores foi capturada por meio da utilização do mapeamento da demanda por parte dos pesquisadores da área pelo espaço editorial disponibilizado por periódicos nacionais. Foram selecionados todos os periódicos brasileiros contidos no Qualis da área de Administração, Contabilidade e Turismo, com classificação em extrato igual ou superior a B2 (tomando como base o ano de 2011), que pudessem veicular artigos científicos sobre temas ligados à área de Gestão de Operações.

A tarefa de seleção dos artigos que versavam sobre Gestão de Operações para inclusão no estudo foi realizada, inicialmente, por meio da leitura do título e do conjunto das palavras-chave em $100 \%$ dos 3.224 artigos contidos nas 394 edições dos 13 periódicos selecionados para a pesquisa (BAR, G\&P, Produção, RAC, RAC eletrônica, RAE, RAE eletrônica, RAM, BBR, RAUSP, REAd, BASE e O\&S). Por meio de uma primeira triagem, foram sumariamente descartados os artigos que não apresentavam nenhuma chance de pertencer à área de Gestão de Operações, a partir da análise do título e das palavraschave. Uma segunda fase da tarefa de seleção de artigos para compor o corpus de análise desta parte do estudo consistiu na leitura do resumo de todos os artigos que não haviam sido eliminados na etapa anterior. Quando, mesmo depois da leitura do resumo, ainda restava dúvida quanto à adequação da inclusão do artigo no estudo, procedeu-se à identificação da origem acadêmica dos autores e à avaliação das referências bibliográficas utilizadas em busca de sinais que pudessem evidenciar sua aderência (ou não) à área de Gestão de Operações. A identificação de autores com raízes acadêmicas em Administração da Produção ou Engenharia de Produção, em conjunto com a utilização de referências a autores da área e/ou a trabalhos publicados em periódicos científicos da área (JOM, IJO\&PM, IJPE, Joscm, G\&P e Produção, entre outros) ou congressos da área de Gestão de Operações (Simpoi, GOLAnpad, Poms, Euroma, entre outros) foi considerada evidência positiva para a inclusão do artigo no estudo.

Após a definição dos artigos classificados como pertinentes à área de Gestão de Operações, foi realizada sua categorização temática atribuindo-se um código a cada artigo, de acordo com o mapeamento de temas em Gestão de Operações proposto por Peinado e Graeml (2013). Para realizar 
essa classificação foram analisados conjuntamente o título, as palavras-chave, o resumo e, nos casos em que isso não era suficiente, o texto completo de cada um dos 598 artigos que haviam sido préselecionados.

\section{Coleta de dados da perspectiva dos professores - análise de conteúdos programáticos}

Como segunda fonte de dados para capturar a perspectiva dos professores, foi, então, realizado um levantamento dos conteúdos programáticos ou ementas das disciplinas de Gestão de Operações dos cursos de Administração. O levantamento considerou apenas as disciplinas obrigatórias que faziam parte das matrizes curriculares dos 47 cursos mencionados anteriormente. Disciplinas optativas (livres e eletivas), atividades complementares, estágio supervisionado e trabalho de conclusão de curso (TCC) não foram levados em conta na análise. O levantamento dos conteúdos foi realizado mediante minuciosa análise da matriz curricular mais recente publicada no website de cada curso avaliado. A pesquisa levantou um montante de 170 registros de disciplinas obrigatórias ligadas à Gestão de Operações, o que resultou em uma média de 3,62 disciplinas por curso. Procurou-se categorizar os assuntos dos conteúdos programáticos de acordo com o mapeamento consolidado de temas proposto por Peinado e Graeml (2013). Adotou-se o critério de registrar o número de vezes que um assunto aparecia nas ementas das 170 disciplinas. Desta forma, foram contabilizadas 559 menções a temas de Gestão de Operações. O número de registros por tema foi então relativizado na forma percentual, dividindo-se a quantidade de menções a cada temática por 559 (total de menções).

\section{Coleta de dados da perspectiva dos praticantes - análise dos sistemas de produção}

Nesta parte da pesquisa, buscou-se levantar a importância prática dos diversos temas da Gestão de Operações nos processos produtivos adotados pelas empresas nacionais de manufatura industrial. Isto também foi realizado utilizando-se o mapeamento consolidado de temas em Gestão de Operações, elaborado por Peinado e Graeml (2013), como base para a classificação das práticas adotadas por um conjunto de empresas montadoras do setor automotivo.

Para tal foram realizadas, inicialmente, entrevistas semiestruturadas com os executivos diretamente responsáveis pelo sistema de produção adotado por quatro grandes montadoras do setor automotivo. O objetivo era levantar informações sobre o sistema de produção adotado, partindo-se do pressuposto que sua análise minuciosa permitiria revelar os temas em Gestão de Operações mais valorizados na prática diária daquelas organizações. A Tabela 3 caracteriza as empresas estudadas, sem identificá-las, uma vez que não se obteve autorização expressa para isso.

Tabela 3

Caracterização das Empresas Estudadas

\begin{tabular}{clccc}
\hline Empresa & Descrição da planta pesquisada & \multicolumn{2}{c}{ Participação no mercado nacional (2013) } \\
Automóveis & $\begin{array}{c}\text { Comerciais } \\
\text { leves }\end{array}$ & $\begin{array}{c}\text { Caminhões e } \\
\text { onnibus }\end{array}$ \\
\hline A & Montadora de veículos de transporte comercial & - & - & $9,7 \%$ \\
B & Montadora de veículos de passeio & $23,5 \%$ & $15,4 \%$ & - \\
C & Montadora de veículos de passeio & $6,3 \%$ & $14,2 \%$ & - \\
D & Montadora de motores de veículos de passeio & $21,0 \%$ & $23,7 \%$ & - \\
\hline
\end{tabular}

Nota. Fonte: Associação Nacional dos Fabricantes de Veículos Automotores. (2014). Anuário da Indústria Automobilística Brasileira - 2014 (p. 124). São Paulo, SP; Brasília, DF: Autor. Recuperado de http://www.virapagina.com.br/anfavea2014/\#I

A amostra formada por essas quatro empresas se justifica pela facilidade de contato para a realização das entrevistas, uma vez que todas as empresas possuem planta na região metropolitana de 
Curitiba e por se acreditar que empresas montadoras do ramo automotivo têm seu processo de Gestão de Operações bastante amadurecido, comparativamente a outras empresas industriais, em decorrência da tradição e competitividade do setor, que determina fortes exigências de desempenho no dia a dia e adequação a várias normativas de qualidade. Além disso, as empresas montadoras do ramo automotivo, segundo dados de 2012, disponibilizados pela Associação Nacional dos Fabricantes de Veículos Automotores (Anfavea, 2014), representam 18,7\% do Produto Interno Bruto brasileiro.

As entrevistas individuais semiestruturadas foram realizadas pessoalmente com indivíduos considerados chave na implantação, manutenção e/ou operacionalização do sistema de produção adotado pelas organizações. As entrevistas permitiram identificar que cada uma das quatro empresas pesquisadas reúne e formaliza o sistema de produção adotado em um documento estruturado, que traduz as diretrizes básicas adotadas, tais como missão, valores, princípios e ferramentas da Gestão de Operações que a organização valoriza. A adoção plena, na prática, dos preceitos destes documentos foi externada por todos os entrevistados em declarações como: "O sistema de produção [referindo-se ao documento] é uma verdadeira cartilha que norteia nossas ações nas linhas de produção", ou então: "Constantemente são oferecidos cursos de aprimoramento e divulgação do nosso sistema de produção contido neste documento", ou ainda: "Todos os funcionários têm conhecimento do nosso sistema de produção".

Foram utilizados quatro documentos, um para cada organização, como fonte de dados para este levantamento baseado em análise de conteúdo, os quais são apresentados na Tabela 4, a seguir.

Tabela 4

Fontes Documentais Utilizadas na Pesquisa

\begin{tabular}{clc}
\hline Empresa & Fonte documental utilizada & Número de páginas \\
\hline A & VPS booklet & 68 \\
B & Manual SPVW & 176 \\
C & SPR management book & 49 \\
D & Manual WCM (World Class Manufacturing) & 289 \\
\hline
\end{tabular}

Nota. Fonte: elaborado pelos autores.

Os entrevistados também informaram que o sistema de produção adotado em suas organizações é de abrangência corporativa, o que significa que todas as plantas industriais que compõem cada uma das empresas estudadas adotam, em âmbito mundial, as mesmas práticas de Gestão de Operações descritas e formalizadas nestes documentos. Este nível de abrangência representa uma importante justificativa para o uso desses documentos como objeto de análise para a realização da pesquisa.

O conteúdo das fontes documentais apresentadas na Tabela 4 foi analisado com o auxílio do software NVivo versão 9. Os quatro arquivos digitais dos documentos foram inseridos como arquivos de categoria fonte no NVivo. Foram criados 45 nós (recipientes digitais que permitem reunir materiais relacionados com a finalidade de auxiliar a procura de padrões e ideias), um para cada um dos 45 temas propostos no mapeamento consolidado de temas em Gestão de Operações (Peinado \& Graeml, 2013). Após a inserção das quatro fontes documentais e da criação dos nós, procedeu-se a uma minuciosa análise de conteúdo das fontes por meio da criação de referências. Uma a uma, cada referência foi criada à medida que um trecho do texto (frase, sentença, parte de parágrafo ou parágrafo inteiro) era analisado e seu conteúdo associado a um ou mais dos 45 nós. O número de registros por tema foi, então, relativizado na forma percentual, dividindo-se o número de menções ao tema pelo total de referências assim obtidas (2.057). 


\section{Apresentação dos Resultados}

\section{Análise direta do valor atribuído às temáticas de gestão de operações na survey}

\section{Perfil profissional dos respondentes}

A Tabela 5 apresenta os resultados obtidos pelo cruzamento do perfil profissional dos respondentes com os cinco estratos da amostragem (pesquisadores mais destacados, professores de IES envolvidos em pesquisa, professores dos cursos CPC 5, professores dos cursos CPC 3 e praticantes).

Tabela 5

\section{Perfil Profissional dos Respondentes}

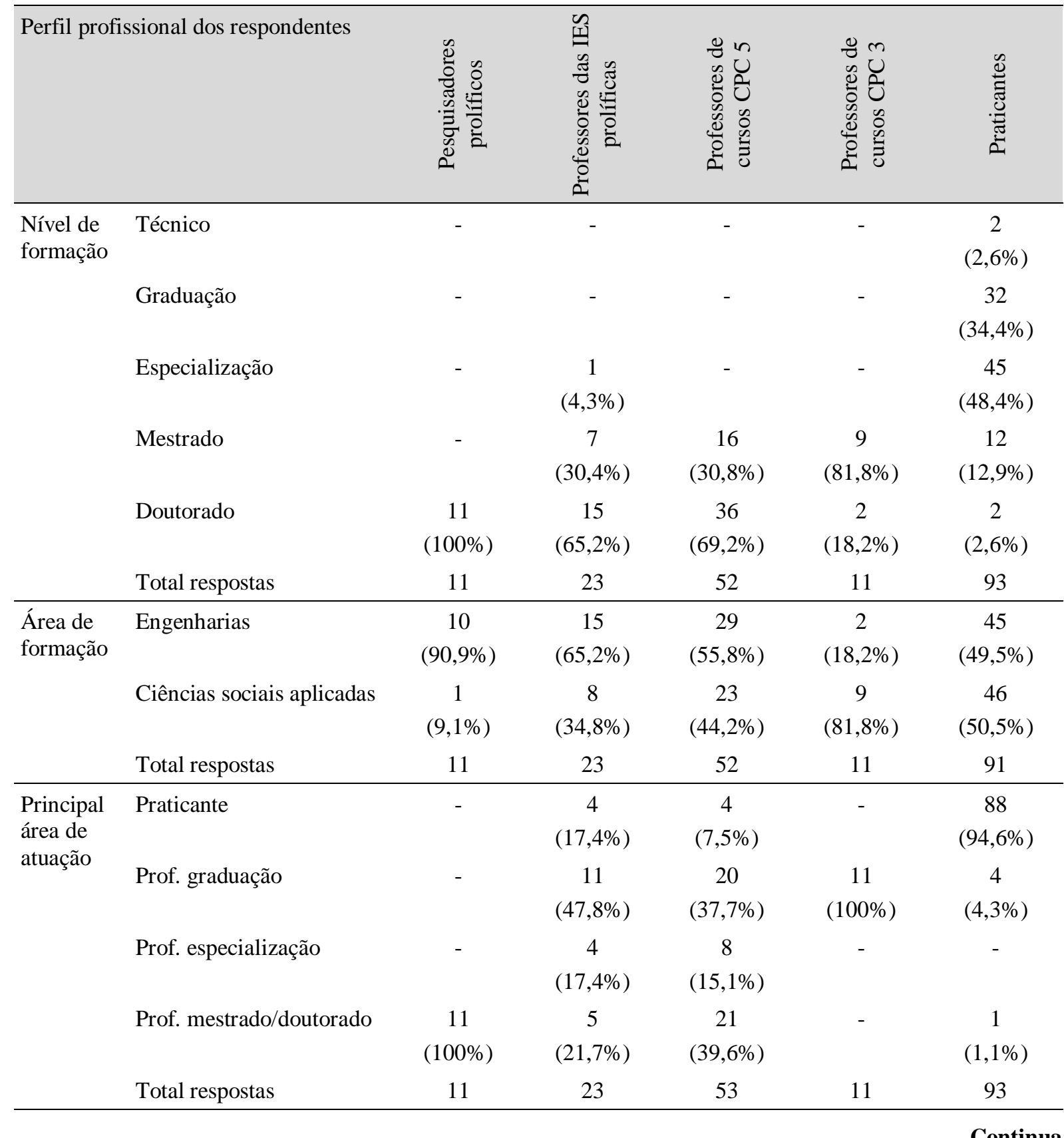




\section{Tabela 5 (continuação)}

\begin{tabular}{|c|c|c|c|c|c|c|}
\hline \multicolumn{2}{|c|}{ Perfil profissional dos respondentes } & \multirow{2}{*}{ 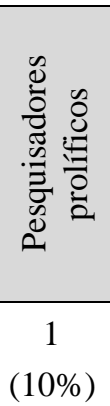 } & \multirow{2}{*}{ 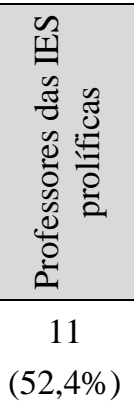 } & \multirow{2}{*}{ 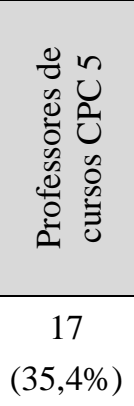 } & \multirow{2}{*}{ 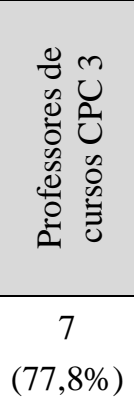 } & \multirow{2}{*}{ 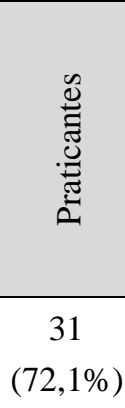 } \\
\hline \multirow{4}{*}{$\begin{array}{l}\text { Área de } \\
\text { atuação } \\
\text { adicional }\end{array}$} & Praticante & & & & & \\
\hline & Prof. graduação & $\begin{array}{c}3 \\
(30 \%)\end{array}$ & $\begin{array}{c}6 \\
(28,6 \%)\end{array}$ & $\begin{array}{c}23 \\
(47,9 \%)\end{array}$ & $\begin{array}{c}2 \\
(22,2 \%)\end{array}$ & $\begin{array}{c}12 \\
(27,9 \%)\end{array}$ \\
\hline & Prof. mestrado/doutorado & $\begin{array}{c}6^{*} \\
(60 \%)\end{array}$ & $\begin{array}{c}4 \\
(19 \%)\end{array}$ & $\begin{array}{c}8 \\
(16,7 \%)\end{array}$ & - & - \\
\hline & Total respostas & 10 & 21 & 48 & 9 & 43 \\
\hline
\end{tabular}

Nota. Fonte: elaborado pelos autores, com base nos dados da pesquisa.

*Seis respondentes indicaram a mesma área de atuação como sendo principal e secundária.

Em relação ao nível de formação dos respondentes, os resultados indicam que, praticamente, todos os professores são mestres ou doutores, com uma predominância de mestres nos cursos com CPC 3. Os pesquisadores mais prolíficos são todos doutores, como já era de se esperar. No entanto 85,4\% dos praticantes cursaram até a graduação ou especialização e apenas $14,6 \%$ possuem mestrado ou doutorado.

Em relação à área de formação dos respondentes, os resultados apresentam uma estreita ligação da Administração com as Engenharias, na área de Gestão de Operações. A formação dos praticantes se mostrou praticamente dividida ao meio, sendo 49,5\% deles com formação na área das Engenharias e 50,5\% com formação em Administração. A área de formação dos professores também ficou praticamente dividida, 46,4\% deles com formação na área das Engenharias e 53,6\% com formação na Administração. Os resultados parecem indicar que isso faz parte do perfil da área, formada, em uma parte, por engenheiros com alguma formação em administração; e, em outra parte, por administradores com interesse pela engenharia. Os resultados também podem ser, de certa forma, justificados pelo fato de a origem da Gestão de Operações ter-se dado na Engenharia. Com relação aos pesquisadores mais prolíficos na publicação de artigos sobre Gestão de Operações, os resultados indicam que 90,9\% têm formação em nível de graduação nas Engenharias. É, ainda, digno de nota o fato de, apenas entre os professores dos cursos CPC 3, os administradores prevalecerem sobre os engenheiros, o que, aliás, dáse de forma significativa, com nove dos 11 participantes provenientes da área das ciências sociais aplicadas.

Os resultados obtidos em relação à área de atuação principal demonstram uma nítida separação entre dois estratos principais da amostra. Pode-se observar que $94,6 \%$ dos praticantes têm esta atividade como principal área de atuação e que $91,8 \%$ dos professores e pesquisadores têm a docência como sua principal área de atuação. Isto é importante para esta pesquisa, em que se procura identificar diferenças na forma de perceber a Gestão de Operações, a partir do tipo de atividade realizada pelo participante da pesquisa.

Em relação à área de atuação adicional, os resultados apontam que 55,2\% dos professores das disciplinas relacionadas à Gestão de Operações também atuam como praticantes em atividades consideradas por eles como secundárias. Estes resultados permitem inferir que grande parte dos professores do tema apresenta experiência prática de mercado. Como se poderia esperar, em virtude do nível de dedicação necessário à pesquisa, apenas um dos pesquisadores mais prolíficos declarou atuar também como praticante. 


\section{Identificação das dimensões dos temas de Gestão de Operações}

Foram calculadas as médias das respostas obtidas para cada uma das questões que compunham o questionário aplicado, discriminadas em função do grupo de respondentes. A seguir, foi realizada a comparação das médias pela ANOVA com testes post hoc de Tukey. A Tabela 6 apresenta os valores das médias obtidas para pesquisadores, professores e praticantes.

Tabela 6

Médias Obtidas Para Cada Temática, Discriminadas em Função da Categoria Profissional (Pesquisadores, Professores e Praticantes) na Survey

\begin{tabular}{lllllll}
\hline Temáticas consolidadas de Gestão de Operações & \multicolumn{2}{c}{ Pesquisadores } & \multicolumn{2}{c}{ Professores } & \multicolumn{2}{c}{ Praticantes } \\
\cline { 2 - 6 } & Média & $\begin{array}{l}\text { Desvio } \\
\text { padrão }\end{array}$ & Média & $\begin{array}{l}\text { Desvio } \\
\text { padrão }\end{array}$ & Média & $\begin{array}{l}\text { Desvio } \\
\text { padrão }\end{array}$ \\
\hline
\end{tabular}

\section{Estratégia de operações}

\begin{tabular}{lllllll} 
1.1 Estratégias e políticas de produção & 6,17 & 1,27 & 6,18 & 1,43 & 6,24 & 1,07 \\
1.2 Gerenciamento de operações globais & 5,00 & 2,00 & 5,56 & 1,33 & 5,34 & 1,34 \\
\hline
\end{tabular}

2. Gestão da rotina de operações

2.1 Gerenciamento da produção e processos

2.2 PCP das operações

\begin{tabular}{cccccc}
6,08 & 1,00 & 6,19 & 1,21 & 6,37 & 0,74 \\
6,33 & 0,89 & $6,15^{*}$ & 1,29 & $6,64^{*}$ & 0,62 \\
6,17 & 0,83 & 6,07 & 1,25 & 6,29 & 1,00 \\
6,00 & 0,85 & $6,04^{*}$ & 1,21 & $6,45^{*}$ & 0,78 \\
5,50 & 1,09 & $4,89^{*}$ & 1,52 & $5,44^{*}$ & 1,31 \\
\hline $5,25^{*}$ & 1,14 & $5,43^{*}$ & 1,30 & $6,13^{*}$ & 0,76 \\
\hline 5,42 & 1,16 & 5,70 & 1,31 & 5,80 & 0,92 \\
\hline
\end{tabular}

2.3 Mensuração de desempenho e produtividade

2.4 Planejamento e análise de capacidade

2.5 Contabilidade de custos para gerência em operações

2.6 Gerenciamento das informações de operações

2.7 Localização de plantas, projeto e leiaute

$5,42, \quad 1,16 \quad 5,70, \quad 1,31 \quad 5,80, \quad 0,92$

\section{JIT - Manufatura enxuta}

3.1 Sistemas de produção enxuta (inclui JIT, TOC)

\begin{tabular}{rrrrrr}
5,67 & 0,78 & $5,75^{*}$ & 1,26 & $6,15^{*}$ & 0,98 \\
5,00 & 1,28 & 5,48 & 1,33 & 5,67 & 1,41 \\
4,75 & 1,22 & 4,72 & 1,45 & 4,52 & 1,73 \\
\hline
\end{tabular}

3.2 Sistemas de manufatura flexível

3.3 Automação CIM - CAD/CAM

\section{Gestão da qualidade}

\begin{tabular}{lllllll} 
4.1 Gerenciamento da qualidade & 5,75 & 1,06 & 5,71 & 1,30 & 5,61 & 1,38 \\
4.2 Gestão da qualidade total & 5,33 & 0,98 & 5,60 & 1,35 & 5,45 & 1,49 \\
4.3 Normalização e certificação para a qualidade & 5,17 & 0,94 & 5,08 & 1,38 & 5,21 & 1,47 \\
\hline
\end{tabular}

\section{Logística e cadeia de suprimentos}

5.1 Logística, transporte e distribuição

5.2 Gerenciamento de materiais e estoques

5.3 Sistemas de compras e suprimentos

5.4 Gestão da cadeia de suprimentos

5.5 Gestão da demanda

5.6 Logística internacional e global sourcing

5.7 Estratégias e práticas logísticas

\section{Ergonomia e organização do trabalho}
6.1 Projeto, mensuração e melhoria do trabalho
6.2 Gerenciamento de RH em operações

$\begin{array}{cccccc}6,25 & 0,97 & 6,23 & 1,15 & 6,13 & 0,91 \\ 6,08 & 1,00 & 5,98^{*} & 1,18 & 6,42 * & 0,72 \\ 5,33 & 1,50 & 5,63 & 1,25 & 5,84 & 0,91 \\ 6,50 & 0,80 & 6,20 & 1,13 & 6,11 & 0,90 \\ 6,00 & 0,85 & 5,86 & 1,24 & 6,10 & 0,91 \\ 5,25 & 1,22 & 5,40 & 1,52 & 5,28 & 1,53 \\ 5,27 & 1,85 & 5,81 & 1,23 & 5,97 & 0,83\end{array}$

0,91

0,72

0,91

0,90

0,91

, 83

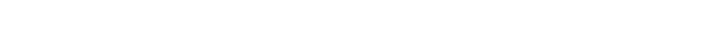

\begin{tabular}{ll|l|l|l|l}
5,08 & 1,08 & $5,12 *$ & 1,37 & $5,68 *$ & 1,20 \\
4,92 & 1,56 & $5,04 *$ & 1,42 & $5,67 *$ & 1,16 \\
\hline
\end{tabular}


Tabela 6 (continuação)

\begin{tabular}{|c|c|c|c|c|c|c|}
\hline \multirow[t]{2}{*}{ Temáticas consolidadas de Gestão de Operações } & \multicolumn{2}{|c|}{ Pesquisadores } & \multicolumn{2}{|c|}{ Professores } & \multicolumn{2}{|c|}{ Praticantes } \\
\hline & Média & $\begin{array}{l}\text { Desvio } \\
\text { padrão }\end{array}$ & Média & $\begin{array}{l}\text { Desvio } \\
\text { padrão }\end{array}$ & Média & $\begin{array}{l}\text { Desvio } \\
\text { padrão }\end{array}$ \\
\hline \multicolumn{7}{|l|}{ 7. Sustentabilidade ambiental operações } \\
\hline 7.1 Questões regulatórias e ambientais operações & 5,58 & 1,16 & 5,10 & 1,35 & 5,30 & 1,18 \\
\hline $7.2 \mathrm{O}$ papel das operações na sustentabilidade & 5,50 & 1,09 & 5,35 & 1,37 & 5,25 & 1,21 \\
\hline 7.3 Estratégia de negócios sustentáveis & 5,50 & 1,38 & 5,20 & 1,46 & 5,21 & 1,23 \\
\hline 7.4 C. S. sustentáveis e logística reversa & 5,83 & 1,19 & 5,74 & 1,33 & 5,37 & 1,61 \\
\hline \multicolumn{7}{|l|}{ 8. Gestão de projetos/desenvolvimento de produtos } \\
\hline 8.1 Gerência de projetos & 5,75 & 1,06 & 5,63 & 1,39 & 5,41 & 1,32 \\
\hline 8.2 Projeto e desenvolvimento de produtos & 5,67 & 1,30 & 5,38 & 1,50 & 5,26 & 1,47 \\
\hline 8.3 Projeto de manufatura & 4,75 & 1,22 & 5,33 & 1,33 & 5,39 & 1,27 \\
\hline \multicolumn{7}{|l|}{ 9. Gestão da inovação e tecnologia } \\
\hline 9.1 Gerência de tecnologia para operações & 4,67 & 1,07 & 5,20 & 1,36 & 5,12 & 1,09 \\
\hline 9.2 Tecnologia de grupo & 4,42 & 1,93 & 4,55 & 1,58 & 4,53 & 1,76 \\
\hline 9.3 Gestão tecnológica/mudança organizacional & 4,83 & 1,53 & 4,52 & 1,37 & 4,92 & 1,31 \\
\hline 9.4 E-business e operações & 4,75 & 1,36 & 4,76 & 1,37 & 4,41 & 1,79 \\
\hline 9.5 Inovação tecnológica & 5,08 & 1,56 & 5,32 & 1,52 & 5,44 & 1,12 \\
\hline \multicolumn{7}{|l|}{ 10. Operações de serviços } \\
\hline 10.1 Estratégias de operações de serviços & 5,92 & 1,16 & $6,00^{*}$ & 1,25 & $5,24 *$ & 1,26 \\
\hline 10.2 Gestão de operações em serviços & 5,92 & 0,79 & $5,90^{*}$ & 1,20 & $5,15^{*}$ & 1,30 \\
\hline 10.3 Produção enxuta em serviços & 4,92 & 1,08 & 5,56 & 1,23 & 5,22 & 1,60 \\
\hline 10.4 Qualidade em operações de serviços & 5,33 & 0,89 & 5,74 & 1,27 & 5,54 & 1,27 \\
\hline 10.5 Logística em operações de serviço & 5,67 & 0,89 & 5,77 & 1,24 & 5,58 & 1,22 \\
\hline 10.6 Ergonomia em operações de serviço & 5,08 & 1,44 & 4,93 & 1,33 & 5,09 & 1,69 \\
\hline 10.7 Sustentabilidade das orgs. de serviço & 5,58 & 1,08 & 5,09 & 1,54 & 4,96 & 1,51 \\
\hline 10.8 Projeto e desenvolvimento de novos serviços & 5,50 & 0,90 & 5,29 & 1,71 & 5,04 & 1,35 \\
\hline 10.9 Gestão da inovação e tecnologia de serviços & 5,50 & 0,90 & 5,26 & 1,74 & 5,13 & 1,34 \\
\hline
\end{tabular}

Nota. Fonte: elaborado pelos autores, com base nos dados da pesquisa.

${ }^{a} \mathrm{O}$ símbolo * indica que a variável é significante a 5\%, de acordo com os testes post hoc de Tukey na ANOVA.

A análise horizontal da Tabela 6 revela uma variação tímida das médias entre a opinião de pesquisadores, professores e praticantes quanto à importância atribuída às temáticas da Gestão de Operações. Dos 45 temas, apenas 10 apresentam significância estatística na diferença da média das respostas entre os grupos. Os praticantes dão um pouco mais de atenção que os professores aos temas: 2.2 PCP das operações; 2.4 Planejamento e análise de capacidade; 2.5 Contabilidade de custos para gerência em operações; 2.6 Gerenciamento das informações de operações; 3.1 Sistemas de produção enxuta; 5.2 Gerenciamento de materiais e estoques; 6.1 Projeto, mensuração e melhoria do trabalho; e 6.2 Gerenciamento de RH em operações. Porém os professores valorizam mais os temas: 10.1 Estratégias de operações de serviços e 10.2 Gestão de operações em serviços. Apesar desses 10 itens apresentarem significância estatística, para nenhum deles a diferença entre as médias é superior a um ponto na escala de sete pontos adotada, o que evidencia que as diferenças de percepção não são 
acentuadas. Em quase todos os casos, as médias obtidas para os professores ficaram entre as médias dos pesquisadores e praticantes. Ainda assim, a dispersão das respostas dos pesquisadores foi maior, o que não permitiu que se encontrassem diferenças estatisticamente relevantes entre as médias dos pesquisadores e dos praticantes. A única exceção foi o tema 2.6 Gerenciamento das informações de operações, para o qual se apuraram diferenças significativas entre pesquisadores e praticantes e também entre professores e praticantes, sendo o tema menos valorizado pelos pesquisadores/professores do que pelos praticantes.

Percebe-se, claramente, com base nas diferenças estatisticamente significativas reveladas entre as médias, conforme elencado na Tabela 6 , que a maioria delas ocorre para temas associados à Gestão da rotina de operações, o que pode indicar que os praticantes dão mais importância a temáticas que os auxiliem em atividades cotidianas do seu trabalho. Esta constatação não é surpreendente, considerando as pressões do ambiente operacional para que as coisas aconteçam. Parece, portanto, coerente a valorização de ferramentas de Gestão de Operações que os instrumentalizem para o bom desempenho dessas atribuições. Este resultado corrobora os achados de Ford et al. (2003), para quem os executivos valorizam o conhecimento como uma fonte de vantagem competitiva, bem como os de Alves et al. (2011), que identificaram a implementação de um sistema de gestão baseado no lean manufacturing como o principal movimento estratégico de produção nas empresas por eles estudadas.

Também não causa surpresa o fato de pesquisadores e praticantes terem opiniões mais dissonantes, com os professores apresentando médias, em geral, entre aquelas obtidas para os dois outros grupos (tendência ainda mais acentuada para os temas em que as diferenças entre as médias foram estatisticamente significativas). Afinal, pesquisadores estão voltados à teorização, enquanto praticantes, como o próprio nome indica, vivem a prática da Gestão de Operações. No meio do caminho, os professores têm a missão de aproximar teoria e prática, desse modo, possibilitando que seus alunos, ao ingressarem no mercado de trabalho, possam se beneficiar da teoria para desenvolver melhor a prática.

Como já discutido, apesar das diferenças entre as médias obtidas para pesquisadores e praticantes terem, em geral, sido maiores que as diferenças para professores e praticantes, tais diferenças não foram significativas no primeiro caso em virtude do maior desvio padrão no caso dos pesquisadores, o que possivelmente decorreu de a amostra de pesquisadores ser muito pequena (apenas 12 pesquisadores).

Por fim, uma constatação interessante é que nenhum tema obteve média inferior a quatro pontos em uma escala que variava desde um ponto, para sem importância, até sete pontos, para extremamente importante. Assim, verificou-se que todos os 45 temas são considerados importantes para a Gestão de Operações por pesquisadores, professores e praticantes.

A análise dos resultados da survey não permitiu, portanto, perceber a existência de um gap significativo entre as percepções de importância atribuída às temáticas de Gestão de Operações, a partir da perspectiva dos pesquisadores, pesquisadores e praticantes, conforme poderia ser esperado, a partir do que foi apurado nos estudos anteriores, realizados por Rynes et al. (2001), Starkey e Madan (2001), Spell (2001) e Abrahamson e Eisenman (2001). Por isso, optou-se por, também, proceder a uma análise indireta do valor atribuído por esses grupos às temáticas, na tentativa de se identificar eventuais diferenças entre o que se diz e o que se faz, entre percepção e ação, conforme discutido anteriormente.

\section{Análise indireta do valor atribuído às temáticas de gestão de operações}

A consolidação dos dados, apresentada na Tabela 7, foi obtida da seguinte forma: a primeira coluna apresenta os temas de Gestão de Operações, conforme Peinado e Graeml (2013). A segunda e terceira colunas elencam a distribuição dos artigos publicados pelos pesquisadores conforme a categoria temática abordada e sua participação relativizada, em forma percentual. A quarta e quinta colunas expõem a classificação por categoria temática do conteúdo programático das disciplinas obrigatórias em Gestão de Operações nos cursos de Administração analisados e sua participação relativizada, dessa forma, refletindo a importância atribuída às temáticas pelos professores. As duas últimas colunas indicam o número de menções às temáticas nos documentos do sistema de produção das organizações pesquisadas e sua participação relativizada, que correspondem à valorização das temáticas a partir da 
perspectiva dos praticantes, nas empresas. Os valores relativizados em forma percentual permitem a comparação entre os níveis de importância atribuídos aos temas de Gestão de Operações a partir das perspectivas da pesquisa, do ensino e da extensão porque capturam a frequência com que essas temáticas aparecem no cotidiano desses profissionais. Afinal, pesquisadores estão muito envolvidos com os artigos acadêmicos que produzem e leem, professores passam boa parte do seu tempo tratando das temáticas contidas nos planos de ensino e ementários das disciplinas que ministram e praticantes precisam levar em conta, nas suas atividades diárias, as determinações contidas nos documentos que tratam do sistema produtivo de suas organizações.

Tabela 7

Comparação da Importância Atribuída às Temáticas de Gestão de Operações a partir das Perspectivas dos Pesquisadores, Professores e Praticantes

\begin{tabular}{|c|c|c|c|c|c|c|}
\hline \multirow{2}{*}{$\begin{array}{l}\text { Temáticas consolidadas de Gestão de Operações } \\
\text { Total de referências }\end{array}$} & \multicolumn{2}{|c|}{ Pesquisa } & \multicolumn{2}{|c|}{ Ensino } & \multicolumn{2}{|c|}{ Prática } \\
\hline & 591 & $100 \%$ & 559 & $100 \%$ & 2057 & $100 \%$ \\
\hline 1. Estratégia de operações & 49 & $\mathbf{8 , 3 \%}$ & 24 & $4,3 \%$ & 100 & $4,9 \%$ \\
\hline 1.1 Estratégias e políticas de produção & 41 & $6,9 \%$ & 24 & $4,3 \%$ & 94 & $4,6 \%$ \\
\hline 1.2 Gerenciamento de operaç̃oes globais & 8 & $1,4 \%$ & 0 & $0,0 \%$ & 6 & $0,3 \%$ \\
\hline 2. Gestão da rotina de operações & 65 & $11,0 \%$ & 151 & $27 \%$ & 523 & $25,4 \%$ \\
\hline 2.1 Gerenciamento da produção e processos & 10 & $1,7 \%$ & 37 & $6,6 \%$ & 147 & $7,1 \%$ \\
\hline 2.2 PCP das operações & 15 & $2,5 \%$ & 36 & $6,4 \%$ & 34 & $1,7 \%$ \\
\hline 2.3 Mensuração de desempenho e produtividade & 12 & $2,0 \%$ & 14 & $2,5 \%$ & 102 & $5,0 \%$ \\
\hline 2.4 Planejamento e análise de capacidade & 3 & $0,5 \%$ & 13 & $2,3 \%$ & 17 & $0,8 \%$ \\
\hline $\begin{array}{l}\text { 2.5 Contabilidade de custos para gerência em } \\
\text { operações }\end{array}$ & 6 & $1,0 \%$ & 0 & $0,0 \%$ & 97 & $4,7 \%$ \\
\hline 2.6 Gerenciamento das informações de operações & 16 & $2,7 \%$ & 21 & $3,8 \%$ & 85 & $4,1 \%$ \\
\hline 2.7 Localização de plantas, projeto e leiaute & 3 & $0,5 \%$ & 30 & $5,4 \%$ & 41 & $2,0 \%$ \\
\hline 3. JIT - Manufatura enxuta & 30 & $5,1 \%$ & 29 & $5,2 \%$ & 376 & $18,3 \%$ \\
\hline 3.1 Sistemas de produção enxuta (inclui JIT, TOC) & 19 & $3,2 \%$ & 22 & $3,9 \%$ & 325 & $15,8 \%$ \\
\hline 3.2 Sistemas de manufatura flexível & 7 & $1,2 \%$ & 5 & $0,9 \%$ & 49 & $2,4 \%$ \\
\hline 3.3 Automação CIM - CAD/CAM & 4 & $0,7 \%$ & 2 & $0,4 \%$ & 2 & $0,1 \%$ \\
\hline 4. Gestão da qualidade & 52 & $8,8 \%$ & 61 & $10,9 \%$ & 422 & $20,5 \%$ \\
\hline 4.1 Gerenciamento da qualidade & 32 & $5,4 \%$ & 33 & $5,9 \%$ & 277 & $13,5 \%$ \\
\hline 4.2 Gestão da qualidade total & 16 & $2,7 \%$ & 19 & $3,4 \%$ & 140 & $6,8 \%$ \\
\hline 4.3 Normalização e certificação para a qualidade & 4 & $0,7 \%$ & 9 & $1,6 \%$ & 5 & $0,2 \%$ \\
\hline 5. Logística e cadeia de suprimentos & 118 & $20,0 \%$ & 171 & $30,7 \%$ & 203 & $\mathbf{9 , 9 \%}$ \\
\hline 5.1 Logística, transporte e distribuição & 10 & $1,7 \%$ & 27 & $4,8 \%$ & 29 & $1,4 \%$ \\
\hline 5.2 Gerenciamento de materiais e estoques & 8 & $1,4 \%$ & 37 & $6,6 \%$ & 59 & $2,9 \%$ \\
\hline 5.3 Sistemas de compras e suprimentos & 8 & $1,4 \%$ & 25 & $4,5 \%$ & 24 & $1,2 \%$ \\
\hline 5.4 Gestão da cadeia de suprimentos & 40 & $6,8 \%$ & 35 & $6,3 \%$ & 20 & $1,0 \%$ \\
\hline 5.5 Gestão da demanda & 10 & $1,7 \%$ & 19 & $3,4 \%$ & 13 & $0,6 \%$ \\
\hline 5.6 Logística internacional e global sourcing & 2 & $0,3 \%$ & 7 & $1,3 \%$ & 1 & $0,0 \%$ \\
\hline 5.7 Estratégias e práticas logísticas & 40 & $6,8 \%$ & 21 & $3,8 \%$ & 57 & $2,8 \%$ \\
\hline
\end{tabular}




\section{Tabela 7 (continuação)}

\begin{tabular}{|c|c|c|c|c|c|c|}
\hline \multirow{2}{*}{$\begin{array}{l}\text { Temáticas consolidadas de Gestão de Operações } \\
\text { 6. Ergonomia e organização do trabalho }\end{array}$} & \multicolumn{2}{|c|}{ Pesquisa } & \multicolumn{2}{|c|}{ Ensino } & \multicolumn{2}{|c|}{ Prática } \\
\hline & 36 & $6,1 \%$ & 14 & $2,5 \%$ & 286 & $13,9 \%$ \\
\hline 6.1 Projeto, mensuração e melhoria do trabalho & 30 & $5,1 \%$ & 10 & $1,8 \%$ & 126 & $6,1 \%$ \\
\hline 6.2 Gerenciamento de RH em operações & 6 & $1,0 \%$ & 4 & $0,7 \%$ & 160 & $7,8 \%$ \\
\hline 7. Sustentabilidade ambiental operações & 53 & $9,0 \%$ & 10 & $1,8 \%$ & 52 & $2,6 \%$ \\
\hline 7.1 Questões regulatórias e ambientais operações & 12 & $2,0 \%$ & 2 & $0,4 \%$ & 12 & $0,6 \%$ \\
\hline $7.2 \mathrm{O}$ papel das operações na sustentabilidade & 13 & $2,2 \%$ & 3 & $0,5 \%$ & 26 & $1,3 \%$ \\
\hline 7.3 Estratégia de negócios sustentáveis & 16 & $2,7 \%$ & 1 & $0,2 \%$ & 12 & $0,6 \%$ \\
\hline $\begin{array}{l}\text { 7.4 Cadeias de suprimento sustentáveis/logística } \\
\text { reversa }\end{array}$ & 12 & $2,0 \%$ & 4 & $0,7 \%$ & 2 & $0,1 \%$ \\
\hline 8. Gestão de projetos/desenvolvimento de produtos & 80 & $13,5 \%$ & 43 & $\mathbf{7 , 7 \%}$ & 77 & $3,7 \%$ \\
\hline 8.1 Gerência de projetos & 28 & $4,7 \%$ & 25 & $4,5 \%$ & 38 & $1,8 \%$ \\
\hline 8.2 Projeto e desenvolvimento de produtos & 52 & $8,8 \%$ & 12 & $2,1 \%$ & 17 & $0,8 \%$ \\
\hline 8.3 Projeto de manufatura & 0 & $0,0 \%$ & 6 & $1,1 \%$ & 22 & $1,1 \%$ \\
\hline 9. Gestão da inovação e tecnologia & 17 & $2,9 \%$ & 9 & $1,6 \%$ & 6 & $\mathbf{0 , 2 \%}$ \\
\hline 9.1 Gerência de tecnologia para operações & 2 & $0,3 \%$ & 3 & $0,5 \%$ & 2 & $0,1 \%$ \\
\hline 9.2 Tecnologia de grupo & 1 & $0,2 \%$ & 0 & $0,0 \%$ & 0 & $0,0 \%$ \\
\hline 9.3 Gestão tecnológica/mudança organizacional & 11 & $1,9 \%$ & 1 & $0,2 \%$ & 3 & $0,1 \%$ \\
\hline 9.4 E-business e operações & 0 & $0,0 \%$ & 2 & $0,4 \%$ & 0 & $0,0 \%$ \\
\hline 9.5 Inovação tecnológica & 3 & $0,5 \%$ & 3 & $0,5 \%$ & 1 & $0,0 \%$ \\
\hline 10. Operações de serviços & 91 & $15,4 \%$ & 47 & $8,4 \%$ & 12 & $\mathbf{0 , 4 \%}$ \\
\hline 10.1 Estratégias de operações de serviços & 9 & $1,5 \%$ & 8 & $1,4 \%$ & 1 & $0,0 \%$ \\
\hline 10.2 Gestão de operações em serviços & 15 & $2,5 \%$ & 12 & $2,1 \%$ & 1 & $0,0 \%$ \\
\hline 10.3 Produção enxuta em serviços & 5 & $0,8 \%$ & 2 & $0,4 \%$ & 0 & $0,0 \%$ \\
\hline 10.4 Qualidade em operações de serviços & 30 & $5,1 \%$ & 10 & $1,8 \%$ & 3 & $0,1 \%$ \\
\hline 10.5 Logística em operações de serviço & 9 & $1,5 \%$ & 3 & $0,5 \%$ & 6 & $0,3 \%$ \\
\hline 10.6 Ergonomia em operações de serviço & 8 & $1,4 \%$ & 2 & $0,4 \%$ & 0 & $0,0 \%$ \\
\hline 10.7 Sustentabilidade das orgs. de serviço & 2 & $0,3 \%$ & 0 & $0,0 \%$ & 0 & $0,0 \%$ \\
\hline 10.8 Projeto e desenvolvimento de novos serviços & 7 & $1,2 \%$ & 9 & $1,6 \%$ & 1 & $0,0 \%$ \\
\hline 10.9 Gestão da inovação e tecnologia de serviços & 6 & $1,0 \%$ & 1 & $0,2 \%$ & 0 & $0,0 \%$ \\
\hline
\end{tabular}

Nota. Fonte: elaborado pelos autores.

${ }^{a}$ Os itens destacados em cinza ficaram entre os 10 de maior incidência para cada perspectiva.

Somando-se os percentuais das células destacadas em cinza, para cada coluna de percentuais da Tabela 7, que representam as 10 temáticas mais valorizadas a partir de cada perspectiva, percebe-se uma concentração da atenção de pesquisadores, professores e praticantes. Respectivamente, 55,5\%, 55,3\% e 75,5\% das preocupações com temáticas de Gestão de Operações desses profissionais recaem sobre apenas 10 temáticas. É nítido, portanto, que não há uma distribuição homogênea de atenção entre todas as temáticas, algumas delas recebendo mais atenção, o que é ainda mais acentuado no caso dos praticantes. 
Uma maior dispersão da ênfase de pesquisa e ensino entre todas as temáticas de Gestão de Operações já poderia ser esperada, uma vez que cabe à academia proporcionar uma compreensão holística das temáticas da área, mesmo que algumas delas possam ter perdido relevância no decurso do tempo, porque elas ajudam o aluno a compreender como se chegou até a situação atual, além de estabelecer um leque de alternativas àquilo que está sendo praticado mais frequentemente pelas empresas, nas suas rotinas de operações.

\section{Consonâncias e divergências entre pesquisa, ensino e prática de gestão de operações}

Como pode ser observado na Tabela 6 , dois temas figuram entre as 10 primeiras colocações nas perspectivas dos pesquisadores, professores e praticantes de Gestão de Operações. Os dois temas são: 1.1 Estratégias e políticas de produção e 4.1 Gerenciamento da qualidade. Da mesma forma, três temas (2.6 Gerenciamento das informações de operações, 3.1 Sistemas de produção enxuta e 6.1 Projeto, mensuração e melhoria do trabalho) figuram conjuntamente entre os mais valorizados por pesquisadores e praticantes. Um tema ( 2.1 Gerenciamento da produção e processos) figura conjuntamente como dos 10 mais relevantes para professores e praticantes. Outros dois temas (5.4 Gestão da cadeia de suprimentos e 8.1 Gerência de projetos) aparecem com frequência na pesquisa e no ensino. Outros 12 temas destacam-se entre os mais importantes para profissionais de alguma das três categorias, mas não despertam o mesmo nível de atenção dos demais. Na Figura 1, apresenta-se a visualização das intersecções dos 20 temas sobre Gestão de Operações que apareceram entre os 10 de maior destaque a partir de alguma das perspectivas.

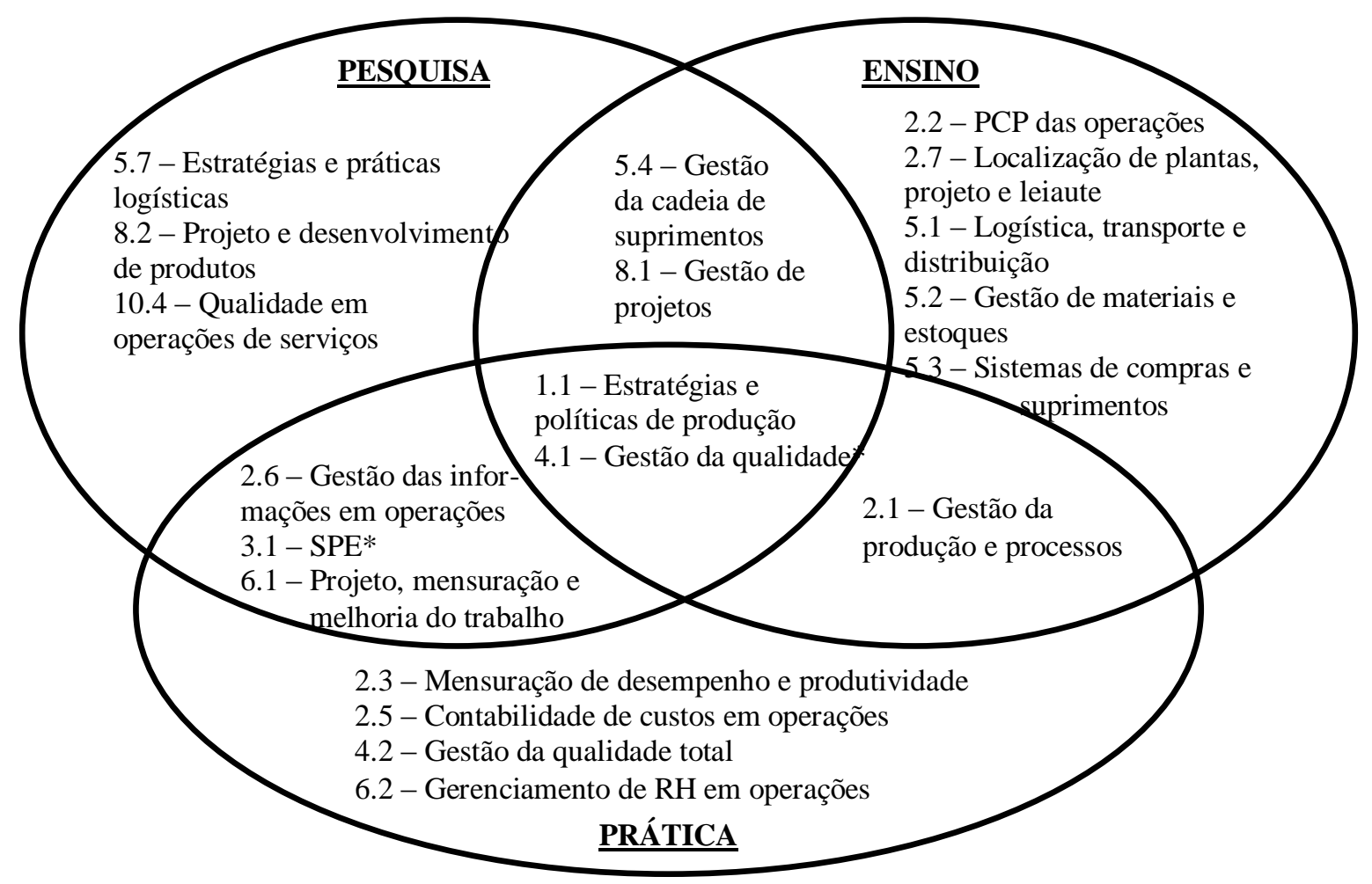

Figura 1. Intersecções entre as Perspectivas dos Pesquisadores, Professores e Praticantes, Considerando-se as 10 Temáticas mais Enfatizadas nas suas Atividades.

Na Figura 1, o símbolo * indica que, apesar de essas temáticas aparecerem entre as 10 mais valorizadas nas perspectivas de interseção, foi detectada grande diferença de importância atribuída por pesquisadores, professores e praticantes. Fonte: elaborado pelos autores, com base nos resultados da pesquisa.

Os dados consolidados na Tabela 7 evidenciam pelo menos quatro temas da Gestão de Operações em que há menor convergência entre o que está sendo pesquisado e ensinado na academia e o que está sendo praticado nas indústrias. 
O primeiro tema corresponde a Sistemas de produção enxuta. Ele até aparece na Figura 1, mas a prática empresarial mostrou um nível relativo de importância de $15,8 \%$, equivalente à primeira colocação entre os temas, contra $3,2 \%$ na pesquisa (equivalente à nona posição) e 3,9\% no ensino (equivalente à $11^{\mathrm{a}}$ posição). $\mathrm{O}$ distanciamento de 12 pontos percentuais entre o escore relativo de praticantes, de um lado, e professores e pesquisadores, de outro, corrobora o entendimento de autores como Alves et al. (2011) e Saurin, Ribeiro e Marodin (2010), que já anunciavam o crescimento do interesse pelo SPE dentro das fábricas brasileiras, desde a década de 1990, mas evidencia o fato de que a temática não desperta o mesmo nível de atenção na academia.

O segundo tema corresponde ao Gerenciamento da qualidade para o qual a prática empresarial mostrou um nível relativo de importância de 13,5\% (a segunda colocação entre os temas) contra 5,3\% na pesquisa (equivalente à quinta posição) e 5,9\% no ensino (também equivalente à quinta posição). Ele também consta na Figura 1 como um dos temas que aparecem entre os 10 mais importantes a partir das três perspectivas, mas o distanciamento de praticamente oito pontos percentuais apresentado pelo escore relativo à prática empresarial e o obtido para pesquisa e ensino permite inferir que o gerenciamento da qualidade continua um tema que demanda muita atenção por parte dos praticantes, conquanto já não interesse tanto a pesquisadores e professores, depois de ter sido exaustivamente discutido na academia ao longo das últimas décadas.

Outro tema que revelou baixa convergência na valorização temática em Gestão de Operações, entre o que está sendo pesquisado e ensinado na academia e o que está sendo praticado pelos gestores de operações, é o Gerenciamento de recursos humanos em operações, com um nível relativo de importância de 7,8\% entre os praticantes (equivalente à terceira colocação entre os temas mais valorizados), contra níveis de apenas $1,0 \%$ na pesquisa e $0,7 \%$ no ensino. O distanciamento de praticamente sete pontos percentuais da prática empresarial também é digno de nota. Mas há de se levar em consideração que a baixa representatividade do tema na pesquisa e no ensino talvez se deva ao fato de o gerenciamento de recursos humanos ser tratado academicamente como uma área do conhecimento independente, o que poderia justificar a baixa ocorrência de tópicos que abordem recursos humanos nas disciplinas ligadas à Gestão de Operações, assim como o desinteresse dos pesquisadores da área por publicar artigos que abordem tópicos relacionados.

Por fim, o quarto tema de dissonância é Contabilidade de custos para gerência em operações, para o qual o nível relativo de importância foi de $4,7 \%$ entre os praticantes (o que equivale à oitava colocação), contrastando com níveis de $1,0 \%$ para a pesquisa e $0 \%$ para o ensino. A baixa importância relativa do tema na pesquisa e no ensino talvez possa ser explicada também pelo fato de o gerenciamento de custos ser uma área do conhecimento independente.

Realizada esta discussão e mesmo reconhecendo que existem temáticas da Gestão de Operações que são igualmente valorizadas por pesquisadores, professores e praticantes, como é o caso das estratégias e políticas de produção e gestão da qualidade, as divergências ocorrem em grau suficiente para que se possa admitir a existência de descompasso entre as prioridades das categorias de profissionais interessados em Gestão de Operações, conforme amplamente apontado na literatura (Levenburg, 1996; Schmenner, Wassenhove, Ketokivi, Heyl, \& Lusch, 2009; Slack, Lewis, \& Bates, 2004; Westbrook, 1994). Contudo, embora os procedimentos metodológicos ora adotados não permitam colocação conclusiva a respeito dos motivos desse descompasso, é razoável aceitar que, de fato, deva haver diferença entre os esforços realizados por profissionais com objetivos tão distintos, de modo que o tom de crítica que normalmente acompanha a discussão das dissonâncias entre o que se pesquisa, o que se ensina e o que se pratica nas organizações parece, ao menos em parte, descabido.

Questões pedagógicas ou de estruturação de cursos podem definir quais conteúdos vão estar associados a que disciplinas para evitar sombreamentos na forma como os alunos são expostos aos saberes. Isso pode representar, como já discutido, o motivo para que tópicos de interface entre a Gestão de Operações e outras áreas não tenham sido contemplados nas ementas de cursos e projetos pedagógicos analisados. Da mesma forma, áreas em que os pesquisadores já não vislumbram possibilidade de grandes avanços teóricos podem oferecer menos estímulo ao desenvolvimento de novas pesquisas, se comparadas a outras ainda pouco exploradas, mesmo que não necessariamente as de maior 
impacto no ambiente operacional de uma empresa. Cabe ressaltar que esta dicotomia entre teoria e prática não é motivada apenas pelos interesses de avanços teóricos dos pesquisadores e pressões do cotidiano gerencial. Também resulta de pressões da sociedade e agendas de interesse em países desenvolvidos que, mais cedo ou mais tarde, também, virão a ser importantes para o cotidiano empresarial local (como, por exemplo, a sustentabilidade das operações produtivas).

Por fim, é natural que praticantes deem mais ênfase àquilo que afeta mais diretamente a sua rotina, mas, ao analisar os sistemas de produção das montadoras, como forma de capturar a importância atribuída por praticantes às diversas temáticas, introduz-se um viés operacional ao resultado. Afinal, os sistemas de produção são o mecanismo utilizado pelas empresas para fazer com que a operação funcione, sem tropeços, no dia a dia.

\section{Conclusão}

A comparação dos resultados obtidos na pesquisa realizada na primeira parte deste trabalho (survey) com os resultados obtidos na segunda parte (medição indireta da relevância dos temas) remete a uma importante reflexão. Aparentemente, quando se pergunta a pesquisadores, professores e praticantes sobre a importância que atribuem às diversas temáticas da Gestão de Operações, chega-se a resultados relativamente uniformes, conforme demonstram as médias atribuídas aos temas, conforme se apresenta na Tabela 6 . Ainda assim, quando se analisa o que os pesquisadores estão estudando, o que os professores estão ensinando e o que os praticantes estão efetivamente fazendo em suas rotinas empresariais, fica evidenciado um descompasso.

Apesar dos resultados interessantes obtidos, que evidenciam diferenças nas temáticas priorizadas por pesquisadores, professores e praticantes em suas atividades, as análises realizadas a partir dos dados coletados precisam ser tomadas com alguma cautela. As diferentes formas de captura dos graus de valorização dos temas de Gestão de Operações pelos profissionais das três categorias, apesar da relativização decorrente do uso de incidências percentuais, apresentam vieses que limitam o alcance da pesquisa. Ao utilizar pesquisas publicadas sob a forma de artigos científicos como modo de avaliar o que valorizam os pesquisadores, pode-se introduzir ruídos causados pela interferência de editores e revisores, como gatekeepers do processo editorial (embora, em geral, estes também sejam pesquisadores, o que deveria contribuir para algum nível de homogeneidade de pensamento). Conteúdos programáticos de disciplinas de Gestão de Operações devem representar o que valorizam os professores da área, mas estão sujeitos a fatores históricos (podem contemplar algo que foi relevante no passado, perdeu relevância, mas continua sendo ensinado apenas por inércia ou comodismo). Como discutido na análise, aspectos que são importantes a qualquer operação produtiva podem estar sendo contemplados por outras disciplinas nos cursos de graduação, que não os diretamente relacionados à Gestão de Operações, então, parecendo negligenciados quando é feita uma análise parcial, que não os considere. No caso da prática empresarial, o fato de terem sido considerados os sistemas de produção como fonte documental de dados sobre a importância atribuída às temáticas gera um viés de priorização de questões mais operacionais e rotineiras dos processos produtivos porque os princípios filosóficos e a estratégia podem ficar escondidos nas entrelinhas. Outra possível limitação a ser destacada desta pesquisa é que o fato de uma temática não ser mencionada não querer dizer, necessariamente, que não seja utilizada. Talvez signifique até o oposto: é algo tão óbvio e incorporado à cultura, estrutura e processos que não precisa ser destacado nos documentos que apresentam o sistema produtivo da organização. Portanto, uma última, mas não menos significativa, limitação, e que precisa ser destacada como uma fragilidade da análise, refere-se à forma como os dados foram coletados para a segunda parte da análise (abordagem indireta).

Apesar (e em função) dessas limitações, considera-se que a discussão realizada sobre a percepção da importância atribuída aos temas da Gestão de Operações pelos seus pesquisadores, professores e praticantes seja importante não só pelos resultados que se pôde obter, mas por estimular o debate sobre interesses de pesquisa, ensino e prática empresarial nas áreas de operações e logística, propiciando uma 
oportunidade adicional para se refletir quanto ao potencial da Gestão de Operações na formação dos administradores do futuro e na atuação daqueles que já se encontram no mercado.

\section{Referências}

Abrahamson, E., \& Eisenman, M. (2001). Why management scholars must intervene strategically in the management knowledge market. Human Relations, 54(1), 67-75. doi: $10.1177 / 0018726701541009$

Alves, A. G., Filho, Nogueira, E., \& Bento, P. E. G. (2011). Análise das estratégias de produção de montadoras de motores para automóveis. Gestão e Produção, 18(3), 603-618. doi: 10.1590/S0104-530X2011000300012

Associação Nacional dos Fabricantes de Veículos Automotores. (2014). Anuário da Indústria Automobilística Brasileira - 2014. São Paulo, SP; Brasília, DF: Autor. Recuperado de http://www.virapagina.com.br/anfavea2014/\#I

Arkader, R. (2003). A pesquisa científica em gerência de operações no Brasil. Revista de Administração de Empresas, 43(1), 70-80. doi: 10.1590/S0034-75902003000100008

Babbie, E. R. (2001). Métodos de pesquisa de survey. Belo Horizonte: UFMG.

Berry, S. E., \& Lancaster, L. M. (1992). Views of production practitioners on the importance of selected POM topics: 1978 and 1989 practitioners compared. Production and Inventory Management Journal, 33(2), 24-31.

Berry, S. E., Watson, H. J., \& Greenwood, W. T. (1978). A survey as to the content of introductory POM course. Academy of Management Journal, 21(4), 699-714. doi: 10.2307/255710

Buffa, E. S. (1980). Research in operations management. Journal of Operations Management, 1(1), 17. doi: 10.1016/0272-6963(80)90005-4

Chalmovich, H. (1999). Por uma relação proveitosa entre universidade de pesquisa e empresas. Revista de Administração, 34(4), 18-22.

Chase, R. B. (1980). A classification and evaluation of research in operations management. Journal of Operations Management, 1(1), 9-14. doi: 10.1016/0272-6963(80)90006-6

Constituição da República Federativa do Brasil de 1988. (2014). [Edições Câmara]. (41a ed.). Brasília: Câmara dos Deputados. Recuperado de http://bd.camara.gov.br/bd/bitstream/handle/bdcamara/17519/constituicao_brasil_41ed.pdf?sequ ence $=1$

Corrêa, H. L., Paiva, E. L., \& Mendes, M. A., Primo (2010). A pesquisa em gestão de operações no Brasil: um breve relato de sua evolução. RAE-Eletrônica, 9(2). Recuperado de http://www.scielo.br/pdf/raeel/v9n2/a02v9n2.pdf. doi: 10.1590/S1676-56482010000200002

Dancey, C. P., \& Reidy, J. (2006). Estatística sem matemática para psicologia (3a ed.). Porto Alegre: Artmed.

Field, A. (2009). Descobrindo a estatística usando o SPSS (2a ed.). Porto Alegre: Artmed.

Ford, E. W., Duncan, W. J., Bedeian, A. G., Ginter, P. M., Rousculp, M. D., \& Adams, A. M. (2003). A pesquisa que faz diferença. Revista de Administração de Empresas, 43(4), 86-101. doi: 10.1590/S0034-75902003000400012 
Goetz, B. E. (1959). Teaching production management. Academy of Management Journal, 2(1), 7-20. doi: $10.2307 / 254551$

Green, T. B., Newsom, W. B., \& Jones, S. R. (1977). A survey of the application of quantitative techniques to production/operations management in large corporations. Academy of Management Journal, 20(4), 669-676. doi: 10.2307/255365

Grynszpan, F. (1999). A visão empresarial da cooperação com a universidade. Revista de Administração, 34(4), 23-31.

Levenburg, N. M. (1996). General management skills: do practitioners and academic faculty agree on their importance? Journal of Education for Business, 72(1), 47-51. doi: $10.1080 / 08832323.1996 .10116825$

Machuca, J. A. D., \& Luque, R. A. (2003). An empirical study of POM teaching in Spanish universities: content of POM courses. International Journal of Operations \& Production Management, 23(1), 15-43. doi: $10.1108 / 01443570310453244$

Marcovitch, J. (1999). A cooperação da universidade moderna com o setor empresarial. Revista de Administração, 34(4) 13-17.

Martins, G., Rossoni, L., Csillag, J. M., Martins, M. E., \& Pereira, S. C. F. (2010). Gestão de operações no Brasil: uma análise do campo científico a partir da rede social de pesquisadores. $R A E$ Eletrônica, 9(2). Recuperado de http://www.scielo.br/pdf/raeel/v9n2/a04v9n2.pdf. doi: $10.1590 /$ S1676-56482010000200004

Paiva, E. L., \& Brito, L. A. L. (2013). Produção científica brasileira em gestão de operações no período 2000-2010. Revista de Administração de Empresas, 53(1), 56-66. doi: 10.1590/S003475902013000100006

Peinado, J., \& Graeml, A. R. (2013). Mapeamento dos temas pertinentes à gestão de operações: uma análise baseada na oferta de espaço editorial pelas revistas e congressos da área. Revista de Gestão da FEA-USP, 20(3), 367-386. doi: 10.5700/rege505

Rynes, S. L., Bartunek, J. M., \& Daft, R. L. (2001). Across the great divide: knowledge creation and transfer between practitioners and academics. Academy of Management Journal, 44(2), 340-355. doi: $10.2307 / 3069460$

Saurin, T. A., Ribeiro, J. L. D., \& Marodin, G. A. (2010). Identificação de oportunidades de pesquisa a partir de um levantamento da implantação da produção enxuta em empresas do Brasil e do exterior. Gestão e Produção, 17(4), 829-841. doi: 10.1590/S0104-530X2010000400015

Schmenner, R. W., Wassenhove, L. van, Ketokivi, M., Heyl, J., \& Lusch, R. F. (2009). Too much theory, not enough understanding. Journal of Operations Management, 27(5), 339-343. doi: 10.1016/j.jom.2009.07.004

Slack, N., Lewis, M., \& Bates, H. (2004). The two worlds of operations management research and practice: can they meet, should they meet? International Journal of Operations \& Production Management, 24(4), 372-387. doi: 10.1108/01443570410524640

Smith, R. D., \& Robey, D. (1973). Research and applications in operations management: discussion of a paradox. Academy of Management Journal, 16(4), 647-657. doi: 10.2307/254697

Spell, C. S. (2001). Management fashions: where do they come from, and are they old wine in new bottles? Journal of Management Inquiry, 10(4), 358-373. doi: 10.1177/1056492601104009

Sprague, L. G. (2007). Evolution of the field of operations management. Journal of Operations Management, 25(2), 219-238. doi: 10.1016/j.jom.2007.01.001 
Starkey, K., \& Madan, P. (2001). Bridging the relevance gap: aligning stakeholders in the future of management research. British Journal of Management, 12(Supl. s1), 3-26. doi: 10.1111/14678551.12.s1.2

Vanalle, R. M., \& Salles, J. A. A. (2011). Relação entre montadoras e fornecedores: modelos teóricos e estudos de caso na indústria automobilística brasileira. Gestão e Produção, 18(2), 237-250. doi: 10.1590/S0104-530X2011000200002

Westbrook, R. (1994). Priority management: new theory for operations management. International Journal of Operations \& Production Management, 14(6), 4-24. doi: $10.1108 / 01443579410062059$

Young, S. T., Baird, B. C., \& Pullman, M. E. (1996). POM research productivity in U.S. business schools. Journal of Operations Management, 14(1), 41-53. doi: 10.1016/0272-6963(95)00038-0 